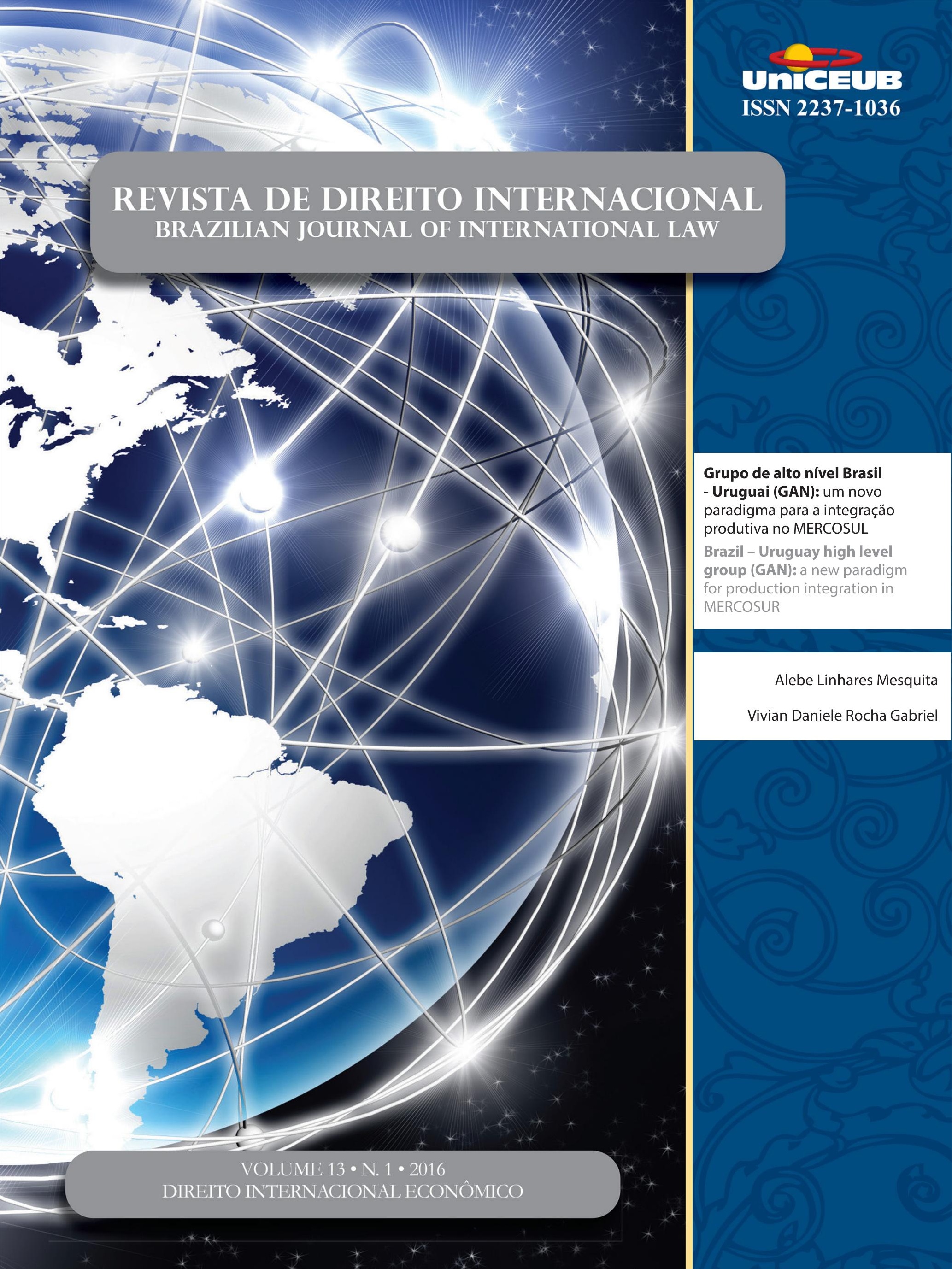




\section{Sumário}

Dossiê Temático: Direito Internacional Econômico.........................................................1

EDITORIAL:

Resultados da III Conferência Bienal da Red DEI ................................................. 3

Michelle Ratton Sanchez-Badin (em nome da Diretoria da Red DEI), Fabio Costa Morosini e Lucas da Silva Tasquetto (em nome dos organizadores da III Conferência da Red DEI)

Direito Internacional Econômico no Brasil: QUem Somos E o QUE faZemos? EvidênCIas EMPÍRICAS DE 1994 A 2014

Michelle Ratton Sanchez Badin, Fabio Costa Morosini e Inaê Siqueira de Oliveira

UM ESPAÇO PARA PENSAR EM ALTERNATIVAS? A ACADEMIA LATINO-AMERICANA DE DIREITO INTERNACIONAL ECONÔMICO FRENTE À ORDEM ECONÔMICA GLOBAL

Nicolás Marcelo Perrone

Grupo de alto Nível Brasil - Urugua (GAN): um Novo paradigma para a INTEgraÇão PRODUTIVA NO MERCOSUL

Alebe Linhares Mesquita e Vivian Daniele Rocha Gabriel

O COMÉRCIO de SERVIÇOS ENTRE Brasil E URUGUAI: LiberalizaÇÃo, DESAFIOS E PERSPECTIVAS DO SETOR DE TECNOLOGIA DA INFORMAÇÃO E COMUNICAÇÃO (TIC) E SOFTWARES

Vivian Daniele Rocha Gabriel e Alebe Linhares Mesquita

Core Labor Standards No Regime de PREFERÊNCIAS TARIFÁrias No MERCOSUL: A NeCESSIDADE DE HUMANIZAÇÃO DO COMÉRCIO INTERNACIONAL

Martinho Martins Botelho e Marco Antônio César Villatore

ACordo TRIMS: FleXibilizaÇão ou Não? Política de CONTEÚdo loCal, PROCESSO PROdUTIVO BÁSICO (PPB) E OS DESAFIOS PARA A INDÚSTRIA BRASILEIRA E A INTEGRAÇÃo LATINO-AMERICANA 100

Natália Figueiredo 
ESTUDIOS DE CASO DE RECHAZOS EN FRONTERA DE EXPORTACIONES ALIMENTARIAS LATINOAMERICANAS POR MOTIVOS RELACIONADOS CON MEDIDAS TÉCNICAS NO ARANCELARIAS.

Sofía Boza, Juan Rozas e Rodolfo Rivers

América do Sul em face dos tratados bilaterais de inVESTimento: RUMO aO RETORNo do EsTADO NA SOLUÇão DE CONTROvÉRSIAS? 133 Magdalena Bas

FutURo DE LOS SISTEMAS NACIONALES DE CIENCIA TECNOLOGÍA E INNOVACIÓN EN LA AGENDA ECONÓMICA DE AMÉRICA LATINA: DEFINIENDO CAMBIOS REGULATORIOS O PROTEGIENDO INVERSIONES 146

Rodrigo Corredor

EL PAPEL DE LAS INSTITUCIONES DE CONTROL FINANCIERO SOBRE LOS DERECHOS HUMANOS EN EL CONTEXTO LATINOAMERICANO 157 Jose Miguel Camacho Castro

CONVERGENCIA REgUlATORIA EN LA ALIANZA DEL PACÍFICO: UN CAPÍTULO INCONCLUSO 170 Rodrigo Polanco Lazo

O CONSTITUCIONALISMO E A COMUNITARIZAÇÃO NO DIREITO INTERNACIONAL: POSSIBILIDADES PARA O COMÉRCIO INTERNACIONAL?

Camilla Capucio

ESCASSEZ HÍDRICA E DIREITO INTERNACIONAL ECONÔMICO: O BRASIL COMO PROTAGONISTA NA TRANSFERÊNCIA DE ÁGUA PARA REGIÕES ÁRIDAS

Douglas de Castro

A Segurança energética como base para maior integração na América Do Sul: à espera DE UM TRATADO MULTILATERAL

Matheus Bassani

Outros Artigos. 246

As PRÁtICAS RESTRITIVAS DA CONCORRÊNCIA NO MERCADO DE CONTRATAÇÃo PÚBLICA EUROPEU .. 248 Alice Rocha da Silva e Ruth M. P. Santos 
Do TRANSNACIONAL PARA O NACIONAL: IOSCO, O MERCADO DE VALORES MOBILIÁRIOS BRASILEIRO E ACCOUNTABILITY

Salem Nasser, Nora Rachman e Viviane Muller Prado

MigRaÇÃo de TRABALHADORES INTELECTUAIS BRASILEIROS PARA O MERCADO INTERNACIONAL: IDENTIFICAÇÃO DE ATOS DE ALICIAMENTO DE EMPREGADOS E MECANISMOS LEGAIS PARA IMPEDIR A APROPRIAÇÃo TECNOLÓGICA E CONCORRÊNCIA DESLEAL ..........................................285 José Carlos Vaz e Dias e João Marcelo Sant'Anna da Costa

THE EASIER WAY TO HAVE "BETTER LAW"? THE MOST-SIGNIFICANT-RELATIONSHIP DOCTRINE AS THE FALLBACK CONFLICT-OF-LAW RULE IN THE PEOPLE'S REPUBLIC OF CHINA

Chi Chung

REFLEXOS JURÍDiCOS DA GOVERNANÇA GLOBAL SUBNACIONAL: A PARADIPLOMACIA E O DIREITO INTERNACIONAL: DESAFIO OU ACOMODAÇÃO 320

Valéria Cristina Farias e Fernando Rei

Matrizes Políticas da JUSTiÇA PENAL INTERNACIONAL. 341 Francisco Rezek

RESPONSABILIDAD INTERNACIONAL DEL ESTADO FRENTE A LUCHA CONTRA LA DISCRIMINACIÓN RACIAL Y ÉTNICA EN ESPAÑA. 348

Edilney Tomé da Mata e Eduardo Biacchi Gomes Correio

The Peace Process in Sierra Leone: an analysis on marriages between culture and CRIME

Gustavo Bussmann Ferreira

Funcionalização e expansão do Direito Penal: o Direito Penal negocial ...............376 Antonio Henrique Graciano Suxberger e Dermeval Farias Gomes Filho

Proteção Internacional do Consumidor e Cooperação Interjurisdicional .396 Héctor Valverde Santana e Sophia Martini Vial

The land rights of indigenous and traditional peoples in Brazil and Australia.... 418 Márcia Dieguez Leuzinger e Kylie Lyngard 
The reception of European ideas in Latin America: the issue of the German sources in Tobias Barreto, A Prominent nineteenth CENTURy BraZilian legal scholar........439 Arnaldo Sampaio de Moraes Godoy

Normas Editoriais ..................................................................................... 461 


\title{
Grupo de alto nível Brasil - Uruguai (GAN): um novo paradigma para a integração produtiva no MERCOSUL*
}

\author{
Brazil - Uruguay high level group (GAN): a \\ new paradigm for production integration in \\ MERCOSUR
}

\author{
Alebe Linhares Mesquita** \\ Vivian Daniele Rocha Gabriel***
}

\section{Resumo}

Presente artigo tem por objetivo investigar as iniciativas de integração produtiva executadas pelo Grupo de Alto Nível Brasil - Uruguai (GAN). Por conseguinte, este estudo é dividido em quatro momentos distintos. Primeiramente, analisa-se a formação institucional do Mercosul, bem com o comércio de bens intra e extrabloco. Em seguida, apresenta-se o Grupo de Alto Nível Brasil, Uruguai, seus projetos e suas conquistas. Na terceira parte, promove-se um estudo sobre a realidade do comércio de bens entre Brasil e Uruguai. Por fim, investigam-se as principais iniciativas de integração produtiva realizadas pelo GAN até o presente momento. A metodologia adotada no desenvolvimento da pesquisa consistiu-se como teórica, bibliográfica e descritiva. O valor deste artigo reside na importância de se traçar novas estratégias de integração produtiva entre o Brasil e os seus países vizinhos, bem como de dar maior dinamicidade ao Mercosul. Em conclusão, pode-se afirmar que as iniciativas de integração produtiva do GAN deveriam ser replicadas no âmbito do Mercosul, especialmente, o programa piloto de segurança aduaneira da cadeia de suprimento de bens; o Acordo Naval e Offshore; e a integração da produção energética por meio da implantação de fontes de energia renovável, como o Parque Eólico de Artilleros.

* Recebido em 23/03/2016

Aprovado em 21/04/2016

** Advogado. Mestrando em Direito Internacional e Comparado pela Universidade de São Paulo (USP). Pesquisador do Centro de Estudos de Estudos do Comércio Global e Investimentos (CCGI) da Escola de Economia de São Paulo da Fundação Getúlio Vargas (EESP/ FGV). E-mail: alebe.mesquita@fgv.br.

*** Advogada. Doutoranda e Mestre em Direito Internacional pela Faculdade de Direito da Universidade de São Paulo (USP). Pesquisadora do Centro de Estudos de Estudos do Comércio Global e Investimentos (CCGI) da Escola de Economia de São Paulo da Fundação Getúlio Vargas (EESP/FGV). E-mail: vivian.d.rocha@ usp.br.
Palavras-Chave: Mercosul. GAN. Integração produtiva.

\section{Abstract}

This paper aims to investigate the production integration initiatives carried out by the Brazil - Uruguay High Level Group (GAN). Therefore, this study is divided into four distinct moments. First, it analyzes the institutional formation of Mercosur, as well as the intra and extra Mercosur's trade in goods. Next, it presents the Brazil - Uruguay High Level Group (GAN), its projects and its achievements. In the third part, it promotes a study on the reality of trade in goods between Brazil and Uruguay. Finally, it investigates the main production integration initiatives undertaken by the GAN until now. The methodology adopted in the development of this research is 
bibliography, descriptive and exploratory. The value of this article resides in the importance of drawing new productive integration strategies between Brazil and its neighboring countries as well as to provide greater dynamism to Mercosur. In conclusion, it can be affirmed that the production integration initiatives of GAN should be replicated within Mercosur, especially, the pilot program of customs security on the supply chain of goods; the Naval and Offshore Agreement; and the energy integration through the implementation of renewable energy sources, such as the Artilleros wind farm.

Keywords: Mercosur. GAN. Production integration.

\section{INTRODUÇÃO}

O comércio de bens é fator fundamental no aprofundamento das relações entre países. As trocas comerciais dinamizam a economia e impulsionam o desenvolvimento dos Estados envolvidos. No processo de integração regional, a redução das barreiras tarifárias entre os países envolvidos impulsiona a produtividade das empresas envolvidas, tornando-as mais competitivas internacionalmente.

Nesse contexto, inserem-se as iniciativas de criação de blocos econômicos regionais voltados à dinamização da economia dos Estados participantes. O Mercosul, instituído em 26 de março de 1991, por meio da adoção do Tratado de Assunção por Argentina, Brasil, Uruguai e Paraguai, caracteriza-se com um dos mais importantes projetos de integração regional do mundo. Desde a sua criação, esse bloco econômico avançou consideravelmente na redução tarifária e no aumento dos fluxos comercias entre os Estados-Parte.

Todavia, em que pese as conquistas até então alcançadas, o Mercosul passa, atualmente, por uma crise político-institucional que impede a negociação de novos temas no âmbito regional. As negociações do bloco concentram-se, majoritariamente, em temas do velho comércio internacional que não refletem o os novos ditames do nexo comércio-investimento-serviços do Século XXI. Ademais, os comércio de bens entre os países do bloco ainda não é completamente livre, sofrendo uma série de barreiras tarifárias e não tarifárias que impedem o livre fluxo de mercadorias entre suas aduanas.

Assim, com o objetivo impulsionar as negociações no âmbito do Mercosul, Brasil e Uruguai instituíram, em junho de 2012, o Grupo de Alto Nível Brasil - Uruguai (GAN) voltado à consolidação de projetos em áreas prioritárias para o aprofundamento da integração bilateral. Essas iniciativas se concentra, notadamente, nos âmbitos da: integração produtiva; ciência, tecnologia e inovação; comunicação e informação; integração da infraestrutura de transportes; livre circulação de bens e serviços; e livre circulação de pessoas.

Destarte, o GAN pretende servir de exemplo para que outros Estados-Parte do Mercosul, também, promovam iniciativas similares, instituindo agendas positivas direcionadas ao avanço do processo de integração regional. Em 3 anos de existência, o Grupo de Alto nível já materializou importantes projetos em todas as suas áreas prioritárias, sendo, portanto, necessário fazer um balanço da sua atuação.

Nesse sentido, o presente artigo tem como objetivo geral investigar os avanços alcançados pelo Grupo de Alto Nível Brasil - Uruguai na promoção da integração produtiva entre os dois países. Para tanto, o presente trabalho encontra-se dividido em quatro momentos distintos. Primeiramente, discorre-se sobre a criação do Mercosul, bem como do comércio de bens intra e extrabloco. Em seguida, apresenta-se o Grupo de Alto Nível Brasil, Uruguai, seus projetos e as conquistas até então alcançadas. Na terceira parte, promove-se um estudo sobre a realidade do comércio de bens entre Brasil e Uruguai. Por fim, analisa-se as principais iniciativas de integração produtiva realizadas pelo GAN até o presente momento.

O desenvolvimento do presente estudo justifica-se pela importância que o tema apresenta na atualidade, uma vez que o estabelecimento de um novo paradigma na relação Brasil e Uruguai não apenas possibilita a solução de velhos obstáculos comerciais entre os dois países, mas também estimula os demais integrantes do MERCOSUL a avançar no processo de integração produtiva do bloco.

\section{Mercosul e o comércio de bens intra e EXTRABLOCO}

O Mercosul consiste em um processo de integração econômica que tem como principal escopo a instituição de um mercado comum, baseado na livre circulação de bens, serviços e fatores produtivos entre Estados-Par- 
te. ${ }^{1}$ Foi criado pelo Tratado de Assunção, firmado em 26 de março de 1991, por Argentina, Brasil, Paraguai e Uruguai e, a partir de 31 de julho de 2012, contou com a entrada efetiva da Venezuela como novo membro.

Convém ressaltar que, em dezembro de 2012, a Bolívia assinou Protocolo de Adesão ao Mercosul, iniciando o processo de união ao bloco, ainda não completamente efetuado. Por ocasião da XLVIII Cúpula dos Chefes de Estado do Mercosul, em 17 de julho de 2015, todos os Estados-Parte aprovaram a entrada da Bolívia no bloco econômico, faltando apenas a aprovação dos parlamentos para sua completa adesão. Registra-se que, além dos Estados - Parte, são Estados Associados do Mercosul: Chile, Peru, Colômbia, Equador, Guiana e Suriname. Assim, todos os países da América do Sul estão vinculados ao Mercosul, seja como Estado-Parte, seja como Associado. ${ }^{2}$

O bloco econômico tem por objetivo a eliminação de restrições tarifárias e não tarifárias; o estabelecimento de uma tarifa externa comum (TEC) para produtos advindos de fora do bloco; a coordenação de políticas macroeconômicas e setoriais, como forma de assegurar as condições adequadas de concorrência; a adoção de políticas comerciais comuns em face de terceiros países; a concertação de posições políticas em face de temas internacionais relevantes e; por fim, o comprometimento dos Estados-Parte em harmonizar suas legislações nacionais em prol do fortalecimento do processo de integração.

Em 29 de novembro de 1991, foi firmado entre os membros originários do Mercosul o Acordo de Complementação Econômica número 18 (ACE n.18), pactuado no âmbito da Associação Latino Americana de Integração (ALADI) e que chancela o vínculo jurídico do bloco com a organização. Esse acordo visa regular as operações comerciais do Mercosul para facilitar a criação de condições necessárias para o estabelecimento do livre comércio entre as nações signatárias, atualizado por meio de seus Protocolos Adicionais.

Cumpre assinalar que os Acordos de Complementação Econômica (ACEs) visam incentivar o desenvol-

1 AMARAL JÚNIOR, Alberto do. Curso de direito internacional público. 4 ed. São Paulo: Atlas, 2013.

2 BRASIL. Ministério das Relações Exteriores. Mercosul. Disponível em: <http://www.itamaraty.gov.br/index.php?option=com_conten $\mathrm{t} \&$ view $=$ article\&id $=686:$ mercosul\&catid $=143 \&$ Itemid $=434 \&$ lang $=$ pt-BR>. Acesso em: 13 jun. 2015. vimento dos países da ALADI por meio da complementariedade dos sistemas produtivos da região. Eles podem regular arranjos de integração sub-regional, como o Mercosul e a Comunidade Andina de Nações (CAN), acordos de livre comércio e acordos de preferências tarifárias fixas. Assim, a sua abrangência é bem variada, podendo englobar todo o universo tarifário ou apenas um número menor de produtos. ${ }^{3}$

No período entre 1991 a 1994, os Estados-Parte do Mercosul estabeleceram uma Zona de Livre Comércio com reduções tarifárias progressivas, lineares e automáticas, com a finalidade de se alcançar, até 31 de dezembro de 1994, uma tarifa zero no universo das suas trocas comerciais ${ }^{4}$. Entretanto, cumpre destacar que listas de exceções a esse cronograma foram estabelecidas, de forma a postergar a completa extinção das barreiras tarifárias entre os Estados-Parte. Ademais, os setores açucareiro e automotivo permaneceram excluídos do acordo.

Em dezembro de 1994, por meio da aprovação do Protocolo de Outro Preto (Protocolo Adicional ao Tratado de Assunção), estabeleceu-se a estrutura institucional do Mercosul e atribuiu-lhe personalidade jurídica internacional ${ }^{5}$. Destarte, a partir de $1^{\circ}$ de janeiro de 1995 , o Mercosul tornou-se uma União Aduaneira com uma Tarifa Externa Comum, que é aplicada com base na Nomenclatura Comum do Mercosul (NCM). A TEC possui níveis de alíquotas distintos que variam de $0 \%$ a $35 \%$, para produtos industrializados, e de $0 \%$ a $55 \%$, para produtos agrícolas, aplicados a cada tipo de mercadoria.

Nesse sentido, o Tratado de Assunção, então Acordo Constitutivo do Mercosul, tem, dentre suas finalidades, a instituição de uma União Aduaneira, caracterizada pela eliminação de barreiras alfandegárias e não alfandegárias entre os países-membros e por uma política comercial comum em relação a outros mercados ${ }^{6}$.

Registra-se que Nomenclatura Comum do Mercosul (NCM) encontra-se em conformidade com o Sistema Harmonizado da Organização Mundial das Aduanas (OMA) que classifica as mercadorias em 6 dígitos. As-

3 BRASIL. Ministério do Desenvolvimento, Indústria e Comércio Exterior. Tipos de acordos no âmbito da ALADI. Disponível em: < http:/ / www. desenvolvimento.gov.br/sitio/interna/interna. php?area $=5 \&$ menu $=412>$. Acesso em: 11 mar. 2016.

4 Vide artigo $1^{\circ}$, alínea a, do Acordo de Complementação Econômica n ${ }^{\circ} 18$.

5 Vide artigo 34 do Protocolo de Ouro Preto.

6 Vide artigo $1^{\circ}$ do Tratado de Assunção. 
sim, utilizam-se 4 dígitos adicionais à categorização estabelecida pela OMA, a fim de se conceder maior nível de detalhamento aos códigos aduaneiros. Todos os bens que são originários do bloco econômico, desde que cumpram os requisitos previstos pelo Regime de Origem do Mercosul, podem ser comercializados pelos países membros sem o pagamento do imposto de importação.

Desde então, o Mercosul vem gradativamente aumentando a participação das suas exportações no mundo. Em 2014, as exportações do bloco econômico para outros parceiros do globo somaram US $\$ 382,7$ bilhões. A evolução das exportações do Mercosul para o mundo pode ser conferida na tabela abaixo.

Tabela 1 - Exportações do Mercosul

\begin{tabular}{|l|c|c|c|c|c|c|}
\hline \multicolumn{7}{|c|}{ Tabela I - Exportações do Mercosul para o Mundo - Valor em } \\
US\$ bilhões \\
\hline Exportadores & 2009 & 2010 & 2011 & 2012 & 2013 & 2014 \\
\hline Brasil & 153,0 & 201,9 & 256,0 & 242,6 & 242,0 & 225,1 \\
\hline Argentina & 55,7 & 68,2 & 84,1 & 80,9 & 76,6 & 68,3 \\
\hline Paraguai & 3,2 & 6,5 & 7,8 & 7,3 & 9,5 & 9,6 \\
\hline Uruguai $^{2}$ & 5,4 & 6,7 & 7,9 & 8,7 & 9,1 & 9,2 \\
\hline Venezuela $^{1}$ & 56,6 & $\mathbf{6 7 , 0}$ & 91,1 & 95,0 & 88,0 & 70,5 \\
\hline Mercosul & $\mathbf{2 7 3 , 8}$ & $\mathbf{3 5 0 , 3}$ & $\mathbf{4 4 6 , 9}$ & $\mathbf{4 3 4 , 5}$ & $\mathbf{4 2 5 , 2}$ & $\mathbf{3 8 2 , 7}$ \\
\hline
\end{tabular}

Fonte: MRE, 2015.7

Dentre os principais grupos de produtos exportados pelo Mercosul, destacam-se os minérios, que, em 2013, tiveram uma participação de $8,8 \%$ no total, seguidos por grãos e sementes $(7,7 \%)$ e automóveis $(5,9 \%)$. Os principais grupos de produtos exportados pelo Mercosul entre 2011 e 2013 encontram-se elencados na tabela abaixo.

Tabela 2 - Exportações do Mercosul

\begin{tabular}{|l|c|c|c|c|}
\hline \multicolumn{2}{|c|}{ Tabela II - Exportações do Mercosul, por principais grupos de } \\
produtos
\end{tabular}

7 BRASIL. Ministério das Relações Exteriores. Mercosul: comércio exterior. 2015. Disponível em: <http://www.investexportbrasil. gov.br/sites/default/files/publicacoes/indicadoresEconomicos/ ComExtMERCOSUL.pdf>. Acesso em: 5 mar. 2016.

\begin{tabular}{|l|c|c|c|c|}
\hline Cereais & 13,8 & 18,2 & 17,0 & $4,1 \%$ \\
\hline $\begin{array}{l}\text { Máquinas } \\
\text { mecânicas }\end{array}$ & 16,1 & 15,9 & 14,9 & $3,6 \%$ \\
\hline Açúcar & 15,5 & 13,4 & 12,3 & $3,0 \%$ \\
\hline Ferro e aço & 13,5 & 12,0 & 9,2 & $2,2 \%$ \\
\hline $\begin{array}{l}\text { Embarcações } \\
\text { flutuantes }\end{array}$ & 1,6 & 1,8 & 8,1 & $2,0 \%$ \\
\hline Subtotal & $\mathbf{1 6 2 , 0}$ & $\mathbf{1 8 0 , 5}$ & $\mathbf{1 9 4 , 2}$ & $\mathbf{4 6 , 8} \%$ \\
\hline $\begin{array}{l}\text { Demais grupos de } \\
\text { produtos }\end{array}$ & $\mathbf{2 7 5 , 0}$ & $\mathbf{2 4 4 , 1}$ & $\mathbf{2 2 1 , 1}$ & $\mathbf{5 3 , 2} \%$ \\
\hline Total & $\mathbf{4 3 7 , 1}$ & $\mathbf{4 2 4 , 6}$ & $\mathbf{4 1 5 , 3}$ & $\mathbf{1 0 0 , 0} \%$ \\
\hline
\end{tabular}

Fonte: MRE, $2015 .^{8}$

Os Estados Unidos se apresenta como o principal destino das exportações do Mercosul. Em 2014, o país apresentou uma participação de 16,2\% no total das exportações do bloco. Na sequência, encontram-se a China $(15,1 \%)$, a Índia $(5,2 \%)$ e os Países Baixos (4,2\%). Os principais destinos das exportações do Mercosul entre 2012 e 2014 estão descriminados na tabela abaixo.

Tabela 3 - Exportações do Mercosul

\begin{tabular}{|c|c|c|c|c|}
\hline Exportações & 2012 & 2013 & 2014 & $\begin{array}{c}\text { Part. no } \\
\text { total } \% \\
\text { em } 2014\end{array}$ \\
\hline Estados Unidos & 32,0 & 30,3 & 62,0 & $16,2 \%$ \\
\hline China & 47,1 & 53,1 & 57,7 & $15,1 \%$ \\
\hline Índia & 6,8 & 4,3 & 20,0 & $5,2 \%$ \\
\hline Países Baixos & 17,6 & 19,7 & 16,1 & $4,2 \%$ \\
\hline Alemanha & 10,0 & 8,9 & 8,7 & $2,3 \%$ \\
\hline Chile & 10,2 & 9,1 & 8,6 & $2,3 \%$ \\
\hline Japão & 9,2 & 9,5 & 7,9 & $2,1 \%$ \\
\hline Cingapura & 3,0 & 2,0 & 7,7 & $2,0 \%$ \\
\hline Espanha & 6,7 & 5,7 & 6,9 & $1,8 \%$ \\
\hline Rússia & 5,0 & 4,9 & 5,9 & $1,5 \%$ \\
\hline Subtotal & 147,5 & 147,5 & 201,6 & $52,7 \%$ \\
\hline $\begin{array}{l}\text { Demais } \\
\text { grupos de } \\
\text { produtos }\end{array}$ & 287,0 & 277,6 & 181,2 & $47,3 \%$ \\
\hline Total & 434,5 & 425,2 & 382,7 & $100,0 \%$ \\
\hline
\end{tabular}

Fonte: MRE, 2015. ${ }^{9}$

8 BRASIL. Ministério das Relações Exteriores. Mercosul: comércio exterior: intercâmbio comercial com o Brasil. 2015. Disponível em: <http://www.brasilexport.gov.br/sites/default/files/publicacoes/ indicadoresEconomicos/ComExtMERCOSUL.pdf>. Acesso em: 27 ago. 2015.

9 BRASIL. Ministério das Relações Exteriores. Mercosul: comércio exterior. 2015. Disponível em: <http://www.investexportbrasil. 
Historicamente, a balança comercial do Mercosul é superavitária. Em 2014, as importações do bloco econômico perfizeram o montante de US\$ 356,3 bilhões. A evolução das importações do Mercosul originárias do mundo pode ser conferida na tabela abaixo.

Tabela 4 - Importações do Mercosul originárias do Mundo.

\begin{tabular}{|l|c|c|c|c|c|}
\hline \multicolumn{7}{|c|}{ Tabela IV - Importações do Mercosul originárias do Mundo US\$ } \\
bilhões \\
\hline Importadores & 2010 & 2011 & 2012 & 2013 & 2014 \\
\hline Brasil & 181,8 & 226,2 & 223,2 & 239,7 & 229,2 \\
\hline Argentina & 56,8 & 74,3 & 68,5 & 73,7 & 64,3 \\
\hline Paraguai & 10,0 & 12,4 & 11,6 & 12,1 & 12,2 \\
\hline Uruguai & 8,6 & 10,7 & 11,7 & 11,6 & 10,8 \\
\hline Venezuela & 36,8 & 48,7 & 59,1 & 45, & 38,8 \\
\hline Mercosul & $\mathbf{2 9 4 , 0}$ & $\mathbf{3 7 2 , 4}$ & $\mathbf{3 7 4 , 0}$ & $\mathbf{3 8 2 , 1}$ & $\mathbf{3 5 6 , 3}$ \\
\hline
\end{tabular}

Fonte: MRE, $2015 .^{10}$

Registra-se que todos os países do Mercosul, com exceção do Paraguai, diminuíram suas importações de 2013 para 2014. Dentre os principais grupos de produtos importados pelo Mercosul, destacam-se os combustíveis, que, em 2013, tiveram uma participação de $15,9 \%$ do total das importações do bloco. Na sequência, encontram-se as máquinas mecânicas $(15 \%)$, máquinas elétricas $(11,4 \%)$ e automóveis $(10,5 \%)$. A Tabela $\mathrm{V}$ indica os principais grupos de produtos importados pelo Mercosul entre 2011 - 2013.

Tabela 5 - Importações do Mercosul, por principais grupos de produtos.

\begin{tabular}{|l|c|c|c|c|}
\hline \multicolumn{2}{|c|}{ Tabela V - Importações do Mercosul, 2011-2013 US\$ Milhões } \\
\hline Importações & 2011 & 2012 & 2013 & $\begin{array}{c}\text { Part. } \\
\text { no total } \\
\% \text { em } \\
2013\end{array}$ \\
\hline Combustíveis & 55,5 & 54,3 & 60,9 & $15,9 \%$ \\
\hline Máquinas Mecânicas & 54,9 & 57,9 & 57,4 & $15,0 \%$ \\
\hline Máquinas Elétricas & 41,5 & 40,8 & 43,7 & $11,4 \%$ \\
\hline Automóveis & 39,9 & 37,6 & 40,2 & $10,5 \%$ \\
\hline
\end{tabular}

gov.br/sites/default/files/publicacoes/indicadoresEconomicos/ ComExtMERCOSUL.pdf>. Acesso em: 5 mar. 2016.

10 BRASIL. Ministério das Relações Exteriores. Mercosul: comércio exterior. 2015. Disponível em: <http://www.investexportbrasil. gov.br/sites/default/files/publicacoes/indicadoresEconomicos/ ComExtMERCOSUL.pdf>. Acesso em: 5 mar. 2016.

\begin{tabular}{|l|c|c|c|c|}
\hline $\begin{array}{l}\text { Produtos químicos } \\
\text { orgânicos }\end{array}$ & 14,6 & 15,4 & 15,7 & $4,1 \%$ \\
\hline Plásticos & 12,9 & 13,0 & 14,1 & $3,7 \%$ \\
\hline $\begin{array}{l}\text { Produtos } \\
\text { farmacêuticos }\end{array}$ & 11,4 & 12,6 & 13,2 & $3,4 \%$ \\
\hline Adubos & 11,8 & 10,8 & 11,0 & $2,9 \%$ \\
\hline $\begin{array}{l}\text { Instrumentos de } \\
\text { precisão }\end{array}$ & 10,2 & 10,0 & 10,4 & $2,7 \%$ \\
\hline Obras de ferro ou aço & 6,2 & $\mathbf{7 , 5}$ & 8,6 & $2,2 \%$ \\
\hline Subtotal & $\mathbf{2 5 8 , 2}$ & $\mathbf{2 5 9 , 9}$ & $\mathbf{2 7 5 , 1}$ & $\mathbf{7 1 , 8} \%$ \\
\hline $\begin{array}{l}\text { Demais grupos de } \\
\text { produtos }\end{array}$ & $\mathbf{1 1 7 , 6}$ & $\mathbf{1 1 8 , 8}$ & $\mathbf{1 0 8 , 2}$ & $\mathbf{2 8 , 2} \%$ \\
\hline Total & $\mathbf{3 7 5 , 8}$ & $\mathbf{3 7 8 , 7}$ & $\mathbf{3 8 3 , 3}$ & $\mathbf{1 0 0 , 0} \%$ \\
\hline
\end{tabular}

Fonte: MRE, 2015. ${ }^{11}$

A China se apresenta como a principal origem das importações do Mercosul. Em 2014, o país asiático apresentou uma participação de 16,5\% no total das importações do bloco. Na sequência, encontram-se os Estados Unidos (16,1\%), a Alemanha (5,3\%) e a Nigéria (3\%). A VI apresenta os 10 principais países de origem das importações do Mercosul no período de 2012 e 2014.

Tabela 6 - Importações do Mercosul.

\begin{tabular}{|l|c|c|c|c|}
\hline \multicolumn{3}{|c|}{ Tabela VI - Importações do Mercosul - 10 principais origens } \\
\hline Importações & 2012 & 2013 & 2014 & $\begin{array}{c}\text { Part. no } \\
\text { total } \% \\
\text { em } 2014\end{array}$ \\
\hline China & 59,1 & 61,7 & 58,8 & $16,5 \%$ \\
\hline Estados Unidos & 58,0 & 56,6 & 57,2 & $16,1 \%$ \\
\hline Alemanha & 19,8 & 20,9 & 19,0 & $5,3 \%$ \\
\hline Nigéria & 8,4 & 10,5 & 10,6 & $3,0 \%$ \\
\hline Coreia do Sul & 11,4 & 11,5 & 10,2 & $2,8 \%$ \\
\hline Itália & 9,3 & 9,8 & 9,1 & $2,5 \%$ \\
\hline México & 11,2 & 10,7 & 9,0 & $2,5 \%$ \\
\hline França & 8,5 & 9,5 & 7,98 & $2,2 \%$ \\
\hline Japão & 10,4 & 9,4 & 7,94 & $2,2 \%$ \\
\hline Ín ia & 6,3 & 7,7 & 7,85 & $2,2 \%$ \\
\hline Subtotal & $\mathbf{2 0 2 , 3}$ & $\mathbf{2 0 8 , 2}$ & $\mathbf{1 9 7 , 6}$ & $\mathbf{5 5 , 5 \%}$ \\
\hline $\begin{array}{l}\text { Demais grupos } \\
\text { de produtos }\end{array}$ & $\mathbf{1 7 1 , 7}$ & $\mathbf{1 7 3 , 9}$ & $\mathbf{1 5 8 , 6}$ & $\mathbf{4 4 , 5 \%}$ \\
\hline Total & $\mathbf{3 7 4 , 0}$ & $\mathbf{3 8 2 , 1}$ & $\mathbf{3 5 6 , 3}$ & $\mathbf{1 0 0 \%}$ \\
\hline
\end{tabular}

Fonte: MRE, 2015. ${ }^{12}$

11 BRASIL. Ministério das Relações Exteriores. Mercosul: comércio exterior: intercâmbio comercial com o Brasil. 2015. Disponível em: <http://www.brasilexport.gov.br/sites/default/files/publicacoes/ indicadoresEconomicos/ComExtMERCOSUL.pdf>. Acesso em: 27 ago. 2015.

12 BRASIL. Ministério das Relações Exteriores. Mercosul: comércio exterior. 2015. Disponível em: < http://www.investexportbrasil. 
Nos últimos cinco anos, também é possível observar que as exportações do Mercosul intrabloco vem crescendo. A tabela VII apresenta essa evolução.

Tabela 7 - Exportações Mercosul Intrabloco.

\begin{tabular}{|l|c|c|c|c|c|c|}
\hline \multicolumn{7}{|c|}{ Tabela VII - Exportações Mercosul Intrabloco } \\
\hline Exportadores & 2009 & 2010 & 2011 & 2012 & 2013 & 2014 \\
\hline Brasil & 19,4 & 26,3 & 32,4 & 27,9 & 29,5 & 25,1 \\
\hline Argentina & 14,9 & 18,6 & 22,6 & 22,1 & 21,5 & 18,4 \\
\hline Paraguai & 1,7 & 2,9 & 3,4 & 3,6 & 3,8 & 4,0 \\
\hline Uruguai & 1,7 & 2,4 & 2,7 & 2,8 & 2,8 & 2,7 \\
\hline Venezuela & 1,5 & 1,7 & 2,1 & 2,0 & 1,7 & 1,6 \\
\hline Mercosul & $\mathbf{3 9 , 2}$ & $\mathbf{5 2 , 0}$ & $\mathbf{6 3 , 2}$ & $\mathbf{5 8 , 3}$ & $\mathbf{5 9 , 3}$ & $\mathbf{5 1 , 8}$ \\
\hline
\end{tabular}

Fonte: MRE, 2015. ${ }^{13}$

No entanto, quando se compara a participação das exportações intrarregionais com as exportações totais dos Estados-Membros, pode-se chegar a algumas importantes conclusões. O Paraguai e o Uruguai, por exemplo, direcionam parte significativa de suas exportações para o Mercosul, representando, respectivamente $41,7 \%$ e $28,8 \%$ do total de suas exportações. O Brasil, por sua vez, destina, apenas, $11,1 \%$ do total de suas exportações para o Mercosul. Ademais, observa-se que a Venezuela ainda está pouco integrada ao bloco, uma vez que a participação de suas exportações em 2014 foram menores do que as de 2009. A tabela VIII apresenta os dados que fundamentam essas afirmações.

Tabela 8 - Participação das Exportações Intraregionais nas Exportações Totais.

\begin{tabular}{|c|c|c|c|c|c|c|}
\hline \multicolumn{7}{|c|}{$\begin{array}{l}\text { Tabela VIII - Participação das Exportações Intraregionais nas } \\
\text { Exportações Totais, por país, em US\$ milhões }\end{array}$} \\
\hline \multirow[b]{2}{*}{ País } & \multicolumn{3}{|c|}{2009} & \multicolumn{3}{|c|}{2014} \\
\hline & $\begin{array}{l}\text { Exp } \\
\text { total }\end{array}$ & $\begin{array}{l}\text { Exp } \\
\text { Intra }\end{array}$ & $\begin{array}{c}\text { Part. } \\
\%\end{array}$ & $\begin{array}{l}\text { Exp } \\
\text { total }\end{array}$ & $\begin{array}{l}\text { Exp } \\
\text { intra }\end{array}$ & $\begin{array}{l}\text { Part. } \\
\% \%\end{array}$ \\
\hline Brasil & 153,0 & 19,4 & $12,7 \%$ & 225,1 & 25,1 & $11,1 \%$ \\
\hline Argentina & 55,7 & 14,9 & $26,7 \%$ & 60,9 & 18,4 & $30,2 \%$ \\
\hline Paraguai & 3,2 & 1,7 & $52,3 \%$ & 9,7 & 4,0 & $41,7 \%$ \\
\hline Uruguai & 5,4 & 1,7 & $31,8 \%$ & 9,3 & 2,7 & $28,8 \%$ \\
\hline Venezuela $^{3}$ & 56,3 & 1,5 & $2,6 \%$ & 68,1 & 1,6 & $2,4 \%$ \\
\hline
\end{tabular}

Fonte: MRE, 2015. ${ }^{14}$

gov.br/sites/default/files/publicacoes/indicadoresEconomicos/ ComExtMERCOSUL.pdf $>$. Acesso em: 5 mar. 2016.

13 BRASIL. Ministério das Relações Exteriores. Mercosul: comércio exterior: intercâmbio comercial com o Brasil. 2015. Disponível em: $<$ http://www.brasilexport.gov.br/sites/default/files/publicacoes/ indicadoresEconomicos/ComExtMERCOSUL.pdf>. Acesso em: 27 ago. 2015.

14 BRASIL. Ministério das Relações Exteriores. Mercosul: comércio
Cumpre ainda destacar que, com base no que dispõe a Decisão do Conselho do Mercado Comum $n^{\circ}$ 58/2010, cada Estado-Membro do Mercosul poderá manter uma lista de exceções à Tarifa Externa Comum (TEC), nos seguintes termos:

(i) República Argentina: até 100 códigos NCM até 31 de dezembro de 2015;

(ii)República Federativa do Brasil: até 100 códigos NCM até 31 de dezembro de 2015;

(iii) República do Paraguai: até 649 códigos NCM até 31 de dezembro de 2019;

(iv)República Oriental do Uruguai: até 225 códigos NCM até 31 de dezembro de $2017^{15}$.

Os Estados-Parte do Mercosul foram autorizados a conservar alguns mecanismos de ajuste das suas tarifas nacionais, por meio dessa lista de exceções, possibilidade esta prevista desde o início da implantação da TEC. Reitera-se, ainda, que essas exceções temporárias podem contemplar níveis de alíquotas inferiores ou superiores às da TEC, desde que não excedam os níveis consolidados na Organização Mundial do Comércio. ${ }^{16}$

Em síntese, pode-se afirmar que a comercialização de bens intra e extra Mercosul vem apresentando crescimento contínuo. No entanto, em que pese o avançado desenvolvimento institucional que o Mercosul alcançou desde a sua criação; os Estados-Parte têm, nos últimos anos, enfrentado diversos obstáculos para avançar processo de integração econômica do bloco. As dificuldades vão desde entraves no fluxo de mercadorias no procedimento alfandegário até a instituição de uma agenda de negociação que corresponda à realidade do comércio mundial do Século XXI.

Apesar do avanço comercial até então alcançado, Oelsner afirma que o Mercosul passa por uma crise de identidade no qual obstáculos e dificuldades aparecem minar o seu processo de consolidação e de adaptação às

exterior: intercâmbio comercial com o Brasil. 2015. Disponível em: <http://www.brasilexport.gov.br/sites/default/files/publicacoes/ indicadoresEconomicos/ComExtMERCOSUL.pdf>. Acesso em: 27 ago. 2015.

15 Vide artigo $1^{\circ}$ da Decisão do Conselho do Mercado Comum $\mathrm{n}^{\mathrm{o}} 58 / 2010$.

16 BRASIL. Ministério do Desenvolvimento, Indústria e Comércio Exterior. Lista de exceções à tarifa externa comum - LETEC. Disponível em:<http://www.desenvolvimento.gov.br/sitio/interna/interna. php?area $=5 \&$ menu $=3378>$. Acesso em: 2 maio 2015 . 
circunstâncias mutáveis. ${ }^{17}$ Nessa linha, Celli e Eleoterio reiteram a necessidade de se redesenhar as relações do Mercosul de modo a facilitar o engajamento do bloco em novos Acordos Preferenciais de Comércio, nos moldes da Aliança do Pacífico, e a flexibilizar o cronograma de negociações entre os Estados-Membros. ${ }^{18}$ Diante da nova dinâmica de negociações comercias, o estabelecimento de acordos bilaterais pode se demonstrar mais adequado para se aprofundar a integração entre os países. Assim, com o propósito de servir como exemplo para o resto do bloco, Brasil e Uruguai decidiram instituir um grupo de alto nível para avançar na sua agenda bilateral no âmbito do Mercosul.

\section{O grupo de alto nível Brasil - Uruguai (GAN)}

Em 31 de Julho de 2012, a Presidenta da República Federativa do Brasil, Dilma Rousseff, e o Presidente da República Oriental do Uruguai, José Alberto Mujica, instituíram o Grupo de Ação de Alto Nível Brasil-Uruguai (GAN) encarregado de consolidar o Plano de Ação para o Desenvolvimento Sustentável e a Integração Brasil-Uruguai. Esse plano abrange áreas prioritárias para o aprofundamento da integração bilateral, notadamente nos âmbitos da: (a) integração produtiva, (b) ciência, tecnologia e inovação, (c) comunicação e informação, (d) integração da infraestrutura de transportes, (e) livre circulação de bens e serviços, e (f) livre circulação de pessoas. ${ }^{19}$

As tarefas específicas do GAN e o Escopo do Plano de Ação se encontram no Comunicado Conjunto Presidencial: Novo Paradigma para a Relação Brasil-Uruguai que estabelece que: (i) o GAN poderá criar subgrupos para cada uma das áreas prioritárias, identificando pontos focais responsáveis, em ambos os governos ${ }^{20}$; (ii) os

17 OELSNER, Andrea. The institutional identity of regional organizations, or mercosur's identity crisis. International Studies Quartely, v. 57, p. 115-127, 2013.

18 CELLI JUNIOR, Umberto; ELEOTERIO, Belisa. O Brasil, o Mercosul e os acordos preferenciais de comércio: alternativas e perspectivas. In: IGLESIAS, Enrique et al. (Org.). Os desafios da América Latina no século 21. Curitiba: Juruá, 2014.

19 BRASIL. Ministério das Relações Exteriores. Comunicado conjunto presidencial: novo paradigma para relação Brasil Uruguai. Nota 192, 31 julho de 2012. Disponível em: <http://goo.gl/M6DA7r>. Acesso em: 27 abr. 2015.

20 Destaca-se que poderão integrar o GAN e seus subgrupos: Ministérios, órgãos públicos, empresas públicas, sociedades de economia mista, institutos de pesquisa e representantes do setor subgrupos poderão reunir-se de forma independente, de acordo com a disponibilidade de seus membros, (iii) as contribuições dos subgrupos serão consolidadas pelas respectivas Chancelarias em um único documento que servirá como plano de ação, podendo este sofrer atualizações por ocasião das subsequentes reuniões do GAN; (iv) o plano de ação deverá prever, para cada projeto ou iniciativa, objetivos gerais e específicos, divisão clara de tarefas e responsabilidades, identificando-se os pontos focais de ambos os Governos e os prazos para a realização de atividades e concretização dos objetivos. ${ }^{21}$

Destaca-se que o Plano de Ação não abrangerá todos os projetos inscritos na agenda bilateral, mas somente aqueles de grande envergadura que detenham um caráter de integração profunda. Assim, inicialmente, previu-se os seguintes projetos para cada área prioritária.

Tabela 9 - Projetos Estratégicos dos Subgrupos de Trabalho do GAN.

\begin{tabular}{|l|l|}
\hline \multicolumn{2}{|c|}{ Tabela IX - Projetos Estratégicos dos Subgrupos de Trabalho } \\
do GAN
\end{tabular}

privado, a critério dos respectivos Governos. Vide parágrafo 6.1 do Comunicado Conjunto Presidencial: Novo Paradigma para Relação Brasil-Uruguai de 31de julho de 2012.

21 BRASIL. Ministério das Relações Exteriores. Comunicado conjunto presidencial: novo paradigma para relação Brasil Uruguai. Nota 192, 31 julho de 2012. Disponível em: <http://goo.gl/M6DA7r>. Acesso em: 27 abr. 2015. 


\begin{tabular}{|c|c|}
\hline $\begin{array}{l}\text { Comunicação e } \\
\text { Informação }\end{array}$ & 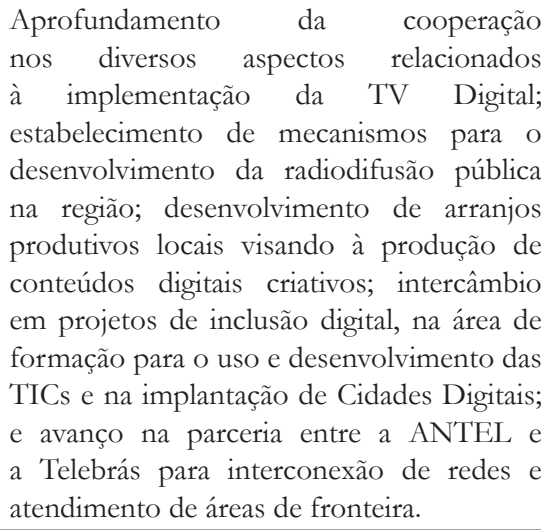 \\
\hline $\begin{array}{l}\text { Integração da } \\
\text { Infraestrutura de } \\
\text { Transportes }\end{array}$ & $\begin{array}{l}\text { Intensificação dos esforços para a } \\
\text { concretização, no prazo mais breve } \\
\text { possível, dos projetos prioritários da área } \\
\text { de transportes: nova ponte sobre o Rio } \\
\text { Jaguarão, reforma da Ponte Internacional } \\
\text { Barão de Mauá, retomada da interconexão } \\
\text { ferroviária por Rivera-Santana do } \\
\text { Livramento, e implantação da Hidrovia } \\
\text { Uruguai-Brasil. }\end{array}$ \\
\hline $\begin{array}{l}\text { Livre Circulação } \\
\text { de Bens e Serviços }\end{array}$ & $\begin{array}{l}\text { Fortalecer os mecanismos de consulta } \\
\text { e de facilitação do comércio bilateral; } \\
\text { acordar procedimentos que possibilitem } \\
\text { o reconhecimento dos sistemas nacionais } \\
\text { de controle, inspeção e certificação, assim } \\
\text { como a equivalência de medidas sanitárias } \\
\text { e fitossanitárias; acordar procedimentos que } \\
\text { possibilitem o reconhecimento mútuo entre } \\
\text { os organismos de avaliação da conformidade. } \\
\text { Os Presidentes também se comprometeram } \\
\text { em concluir um tratado pra evitar a dupla } \\
\text { tributação da renda e do patrimônio. }\end{array}$ \\
\hline $\begin{array}{l}\text { Livre circulação de } \\
\text { pessoa }\end{array}$ & $\begin{array}{l}\text { Avançar na implementação de } \\
\text { procedimentos que facilitem o trânsito de } \\
\text { seus nacionais entre os dois países e que } \\
\text { fortaleçam os laços de integração que os } \\
\text { une. }\end{array}$ \\
\hline
\end{tabular}

Fonte: MRE, 2012.22

Quanto à integração energética, os Presidentes reconheceram a importância da construção de uma linha de transmissão de $500 \mathrm{KV}$ entre San Carlos (Uruguai) e Candiota (Brasil), bem como a relevância da associação entre a Eletrobrás e a Administración Nacional de Usinas y Trasmisiones Eléctricas (UTE) para a construção de parque um eólico no Uruguai. ${ }^{23}$ Convém, ainda, ressaltar que o

22 BRASIL. Ministério das Relações Exteriores. Comunicado conjunto presidencial: novo paradigma para relação Brasil Uruguai. Nota 192, 31 julho de 2012. Disponível em: <http://goo.gl/M6DA7r>. Acesso em: 27 abr. 2015.

23 BRASIL. Ministério das Relações Exteriores. Comunicado conjunto presidencial: novo paradigma para relação Brasil Uruguai. Nota 192, 31 julho de 2012. Disponível em: <http://goo.gl/M6DA7r>. Acesso em: 27 abr. 2015.
GAN abre espaço para a associação de atores públicos e privados que manifestem seu interesse na cooperação bilateral.

As atividades do GAN se iniciaram imediatamente após a reunião do dia 31 de julho de 2012, de modo que até o presente momento duas reuniões plenárias já ocorreram. A primeira aconteceu em Brasília em 9 de julho de 2013, tendo por principal realização a aprovação do Plano de Ação para o Desenvolvimento Sustentável e a Integração Brasil-Uruguai (Plano de Ação).

Esse documento prevê 40 ações estratégicas no curto, médio e longo prazo, com claros objetivos e prazos determinados, bem como divisão de tarefas e responsabilidades. Para tanto, foram instituídos seis grupos de trabalho que refletem cada área prioritária previamente designada ${ }^{24}$. Esses subgrupos devem conduzir suas atividades e reuniões de forma independente, cabendo ao GAN coordená-los por meio do acompanhamento das suas atividades e da avaliação dos avanços registrados.

Ainda durante a primeira reunião plenária, foram assinados: (i) o Acordo sobre Residência Permanente com o Objetivo de Alcançar a Livre Circulação de Pessoas, que prevê um mecanismo simplificado para a permissão da residência permanente a nacionais uruguaios e brasileiros que desejem fixar residência no outro país; e (ii) o Acordo sobre Simplificação de Legalizações em Documentos Públicos, que se aplica aos documentos públicos expedidos no território das partes, que devam ser apresentados no território de outra. ${ }^{25}$

A segunda reunião plenária do GAN ocorreu em 16 de maio de 2014 em Montevidéu. Os subgrupos de trabalhos apresentaram suas propostas e conclusões, que resultaram em quatro importantes documentos, quais sejam:

a. Subgrupo de Integração Produtiva: Protocolo 74 ao ACE-2, que incorpora ao conjunto de acordos comerciais entre os dois países o Acordo Naval e Offshore. Este acordo busca incentivar a integração produtiva no setor naval dos dois países, possibilitando o acesso recíproco de bens e serviços de empresas brasileiras e uruguaias.

24 Os subgrupos instituídos são os de: (i) Integração produtiva; (ii) Ciência, Tecnologia e Inovação, (iii) Comunicação e Informação, (iv) Integração da Infraestrutura de Transportes, (v) Livre Circulação de Bens e Serviços, e (vi) Livre Circulação de Pessoas.

25 BRASIL Ministério das Relações Exteriores. Brasil e Uruguai investem em novo paradigma de integração. 2015. Disponível em: < http:// diplomaciapublica.itamaraty.gov.br/40-brasil-uruguai $>$. Acesso em: 28 abr. 2015. 
b. Subgrupo de Circulação de Bens e Serviços: regulamentação do Protocolo 71 ao ACE-2, que estabelece práticas de facilitação de comércio para dar tratamento aduaneiro mais ágil aos produtos dos dois países.

c. Subgrupo de Livre Circulação de Pessoas: Memorando de Entendimento na Área Previdenciária entre o Banco de Previsión Social de la República Oriental del Uruguay e o Ministério da Previdência Social do Brasil; e Plano para Elaboração Conjunta de um Memorando de Entendimento e Cooperação técnica em temas trabalhistas. ${ }^{26}$

Paralelamente à segunda reunião plenária do GAN, também foram realizados: um seminário sobre oportunidades de investimento Uruguai-Brasil na cadeia naval, petróleo e gás, com autoridades governamentais e representantes dos setores privados dos dois países; e a inauguração da Comissão de Comércio Bilateral Brasil-Uruguai que se apresenta como um canal permanente de comunicação entre autoridades dos dois países para solução de questões pontuais na pauta comercial e para promoção do comércio bilateral. ${ }^{27}$

A terceira reunião plenária do GAN deveria ter sido realizada em Brasília, no segundo semestre de 2015. Todavia, devido à incompatibilidade de agenda dos dois presidentes, a reunião ainda não aconteceu. Espera-se que novos avanços na relação bilateral entre os dois países possam ser concretizados e novos acordos e projetos de integração sejam celebrados. Observa-se que as ações desenvolvidas pelo GAN, em menos de três anos de funcionamento, já o caracterizam como um novo paradigma de integração bilateral, devendo ser utilizado como exemplo no aprofundamento do processo de integração regional do Mercosul. O GAN se apresenta como um novo modelo, uma vez que logra avançar em temas estratégicos, as vezes até mesmo sensíveis, ao contrário do que ocorre atualmente no Mercosul.

Assim, antes de analisar as iniciativas de integração produtiva promovidas pelo GAN, cumpre primeiramente examinar a realidade do comércio bilateral de bens entre os dois países.

26 BRASIL Ministério das Relações Exteriores. Brasil e Uruguai investem em novo paradigma de integração. 2015. Disponível em: <http:// diplomaciapublica.itamaraty.gov.br/40-brasil-uruguai>. Acesso em: 28 abr. 2015.

27 BRASIL Ministério das Relações Exteriores. Brasil e Uruguai investem em novo paradigma de integração. 2015. Disponível em: < http:/ / diplomaciapublica.itamaraty.gov.br/40-brasil-uruguai $>$. Acesso em: 28 abr. 2015.

\section{Comércio bilateral de bens entre Brasil e URUGUal}

O comércio bilateral entre Brasil e Uruguai vem crescendo significativamente nos últimos 10 anos. Apenas em 2009, em razão da crise internacional na região, ele apresentou uma leve queda. ${ }^{28} \mathrm{O}$ Brasil apresenta-se como um destino-chave para a colocação dos produtos uruguaios. O Uruguai, por sua vez, apesar de sua dimensão territorial e populacional, foi considerável parceiro comercial brasileiro, com participação de 1,9\% no total em 2015. ${ }^{29}$

As exportações brasileiras para o Uruguai compõem-se basicamente de produtos básicos e manufaturados. Os básicos representaram $54,5 \%$ do total das exportações em 2015, com destaque para os óleos brutos de petróleo. Os manufaturados, por sua fez, perfizeram $43,6 \%$ do total das exportações, tendo os automóveis e máquinas mecânicas como principais mercadorias. $\mathrm{Na}$ sequência, os semimanufaturados figuraram, no mesmo período, somente por $1,9 \%$ do total das exportações. ${ }^{30}$

Tabela 10 - Composição das Exportações Brasileiras para o Uruguai.

\begin{tabular}{|l|c|c|c|c|c|c|}
\hline \multicolumn{7}{|c|}{ Tabela X - Composição das Exportações Brasileiras para o } \\
Uruguai em US\$ Milhões - FOB \\
\cline { 2 - 8 } Descrição & \multicolumn{2}{|c|}{2013} & \multicolumn{2}{|c|}{2014} & \multicolumn{2}{c|}{2015} \\
\hline Valor & $\begin{array}{c}\text { Part. \% } \\
\text { no total }\end{array}$ & Valor & $\begin{array}{c}\text { Part. } \\
\% \text { no } \\
\text { total }\end{array}$ & Valor & $\begin{array}{c}\text { Part. } \\
\% \text { no } \\
\text { total }\end{array}$ \\
\hline Combustíveis & 446 & $21,5 \%$ & 1.315 & $44,6 \%$ & 1.315 & $48,2 \%$ \\
\hline Automóveis & 322 & $15,5 \%$ & 311 & $10,6 \%$ & 293 & $10,7 \%$ \\
\hline Plásticos & 106 & $5,1 \%$ & 109 & $3,7 \%$ & 97 & $3,6 \%$ \\
\hline $\begin{array}{l}\text { Máquinas } \\
\text { Mecânicas }\end{array}$ & 152 & $7,3 \%$ & 144 & $4,9 \%$ & 95 & $3,5 \%$ \\
\hline Café & 88 & $4,2 \%$ & 103 & $3,5 \%$ & 91 & $3,3 \%$ \\
\hline Carnes & 67 & $3,2 \%$ & 72 & $2,4 \%$ & 61 & $2,2 \%$ \\
\hline $\begin{array}{l}\text { Máquinas } \\
\text { Elétricas }\end{array}$ & 67 & $3,2 \%$ & 66 & $2,2 \%$ & 53 & $1,9 \%$ \\
\hline
\end{tabular}

28 URUGUAI. Instituto de Promocíon de Inversiones y Exportaciones (Uruguay 21). Rio Grande do Sul (Brasil): perfil regional. 2014. Disponível em: <http://www.uruguayxxi.gub.uy/ exportaciones/wp-content/uploads/sites/2/2014/09/InformeUru-XXI-Brasil-Agosto-2014.pdf>. Acesso em: 31 mar. 2015.

29 BRASIL. Ministério Das Relações Exteriores. Uruguai: comércio exterior. 2014, p. 9. Disponível em: <http://www.brasilexport. gov.br/sites/default/files/publicacoes/indicadoresEconomicos/ INDUruguai.pdf>. Acesso em: 30 mar. 2015.

30 BRASIL. Ministério das Relações Exteriores. Uruguai: comércio exterior. 2016. Disponível em: <http://www.investexportbrasil. gov.br/sites/default/files/publicacoes/indicadoresEconomicos/ INDUruguai.pdf>. Acesso em: 6 mar. 2016. 


\begin{tabular}{|l|c|c|c|c|c|c|}
\hline Papel & 47 & $2,3 \%$ & 48 & $1,6 \%$ & 48 & $1,8 \%$ \\
\hline Móveis & 48 & $2,3 \%$ & 53 & $1,8 \%$ & 43 & $1,6 \%$ \\
\hline Açúcar & 47 & $2,3 \%$ & 52 & $1,8 \%$ & 40 & $1,5 \%$ \\
\hline Subtotal & $\mathbf{1 . 3 9 0}$ & $\mathbf{6 7 , 1} \%$ & $\mathbf{2 . 2 7 3}$ & $\mathbf{7 7 , 2} \%$ & $\mathbf{2 . 1 3 6}$ & $\mathbf{7 8 , 3 \%}$ \\
\hline $\begin{array}{l}\text { Outros } \\
\text { produtos }\end{array}$ & $\mathbf{6 8 1}$ & $\mathbf{3 2 , 9 \%}$ & $\mathbf{6 7 2}$ & $\mathbf{2 2 , 8} \%$ & $\mathbf{5 9 1}$ & $\mathbf{2 1 , 7 \%}$ \\
\hline Total & $\mathbf{2 . 0 7 1}$ & $\mathbf{1 0 0 , 0} \%$ & $\mathbf{2 . 9 4 5}$ & $\mathbf{1 0 0 , 0} \%$ & $\mathbf{2 . 7 2 7}$ & $\mathbf{1 0 0 , 0} \%$ \\
\hline
\end{tabular}

Fonte: MRE, 2016. ${ }^{31}$

No que se refere às importações originárias do Uruguai para o Brasil, os produtos manufaturados apresentam maior relevância, somando, $80,1 \%$ da pauta de importações em 2015. Os principais produtos manufaturados importados pelo Brasil do Uruguai são: automóveis, malte não torrado e plástico. Os produtos básicos, por sua vez, atingiram, durante o mesmo período, $18,5 \%$ do total das importações, tendo os cereais e as carnes como principais artigos importados. Os semimanufaturados, por fim, representaram, apenas, 1,4\% dos produtos importados pelo Brasil do Uruguai. ${ }^{32}$

Tabela 11 - Composição das importações Brasileiras originárias do Uruguai.

\begin{tabular}{|c|c|c|c|c|c|c|}
\hline \multirow[b]{2}{*}{ Descrição } & \multicolumn{2}{|c|}{2013} & \multicolumn{2}{|c|}{2014} & \multicolumn{2}{|c|}{2015} \\
\hline & Valor & $\begin{array}{l}\text { Part. } \% \\
\text { no total }\end{array}$ & Valor & $\begin{array}{l}\text { Part. } \% \\
\text { no total }\end{array}$ & Valor & $\begin{array}{l}\text { Part. } \% \\
\text { no total }\end{array}$ \\
\hline Leite & 215 & $12,2 \%$ & 124 & $6,5 \%$ & 174 & $14,3 \%$ \\
\hline Plásticos & 217 & $12,3 \%$ & 205 & $10,7 \%$ & 145 & $11,9 \%$ \\
\hline Automóveis & 162 & $9,2 \%$ & 214 & $11,2 \%$ & 139 & $11,4 \%$ \\
\hline $\begin{array}{l}\text { Amidos e } \\
\text { Féculas }\end{array}$ & 202 & $11,4 \%$ & 216 & $11,3 \%$ & 112 & $9,2 \%$ \\
\hline Carnes & 118 & $6,7 \%$ & 136 & $7,1 \%$ & 96 & $7,9 \%$ \\
\hline Cerais & 232 & $13.1 \%$ & 402 & $21,0 \%$ & 94 & $7,7 \%$ \\
\hline Borracha & 123 & $7,0 \%$ & 105 & $5,5 \%$ & 69 & $5,7 \%$ \\
\hline $\begin{array}{l}\text { Gorduras/ } \\
\text { Óleos }\end{array}$ & 45 & $2,5 \%$ & 61 & $3,2 \%$ & 64 & $5,3 \%$ \\
\hline $\begin{array}{l}\text { Prods. } \\
\text { Diversos das } \\
\text { indústrias } \\
\text { químicas }\end{array}$ & 85,0 & $4,8 \%$ & 59 & $3,1 \%$ & 62 & $5,1 \%$ \\
\hline $\begin{array}{l}\text { Obras de } \\
\text { ferro ou aço }\end{array}$ & 56 & $3,2 \%$ & 46 & $2,4 \%$ & 39 & $3,2 \%$ \\
\hline Subtotal & 1.455 & $82,3 \%$ & 1.568 & $81,7 \%$ & 994 & $81,7 \%$ \\
\hline
\end{tabular}

31 BRASIL. Ministério das Relações Exteriores. Uruguai: comércio exterior. 2016. Disponível em: <http://www.investexportbrasil. gov.br/sites/default/files/publicacoes/indicadoresEconomicos/ INDUruguai.pdf $>$. Acesso em: 6 mar. 2016.

32 BRASIL. Ministério das Relações Exteriores. Uruguai: comércio exterior. 2016. Disponível em: <http://www.investexportbrasil. gov.br/sites/default/files/publicacoes/indicadoresEconomicos/ INDUruguai.pdf $>$. Acesso em: 6 mar. 2016.

\begin{tabular}{|l|c|c|c|c|c|c|}
\hline $\begin{array}{l}\text { Outros } \\
\text { produtos }\end{array}$ & 312 & $17,7 \%$ & 350 & $18,3 \%$ & 223 & $18,3 \%$ \\
\hline Total & 1.767 & $100,0 \%$ & 1.918 & $100,0 \%$ & 1.271 & $100,0 \%$ \\
\hline
\end{tabular}

Fonte: MRE, 2016. ${ }^{33}$

Cumpre destacar a relevância das importações originárias das zonas francas uruguaias para o Brasil. Em 2013, a PepsiCo, empresa localizada na Zona Franca de Colonia, exportou concentrados para a elaboração de bebidas por um total de U\$18,3 milhões. Também sob o regime jurídico das zonas francas uruguaias, exportou-se US\$ 73,2 milhões de trigo e US \$ 34,7 milhões de malte e cevada para o Brasil em 2013.34 O Uruguai dispõe de um avanço sistema de Zonas Francas nas quais as empresas que ali se instalam gozam de isenção tributária bem como outras facilidades administrativas de instalação. Isso concede às empresas que ali se estabelecem grande competitividade no mercado internacional.

Assim, o comércio de bens entre Brasil e Uruguai vem se desenvolvendo progressivamente ao longo dos anos. Entre 2010 e 2014, o intercâmbio comercial entre os dois países cresceu 54,8\%, passando de U\$3,1 bilhões para U\$ 4,8 bilhões. No mesmo período, as exportações aumentaram $92,3 \%$ e as importações, $56,6 \%$. Ademais, cumpre destacar que, usualmente, o saldo da balança comercial apresenta-se favorável ao Brasil, de modo que, nos últimos 10 anos, somente em 2010 o Brasil apresentou deficit de US\$ 43 milhões. ${ }^{35}$ Esses dados podem ser examinados na tabela XII.

33 BRASIL. Ministério das Relações Exteriores. Uruguai: comércio exterior. 2016. Disponível em: <http://www.investexportbrasil. gov.br/sites/default/files/publicacoes/indicadoresEconomicos/ INDUruguai.pdf>. Acesso em: 6 mar. 2016.

34 URUGUAI. Instituto de Promocíon de Inversiones y Exportaciones (Uruguay 21). Rio Grande do Sul (Brasil): perfil regional. 2014. Disponível em: <http://www.uruguayxxi.gub.uy/ exportaciones/wp-content/uploads/sites/2/2014/09/InformeUru-XXI-Brasil-Agosto-2014.pdf>. Acesso em: 31 mar. 2015.

35 BRASIL. Ministério das Relações Exteriores. Uruguai: comércio exterior. 2016. Disponível em: <http://www.investexportbrasil. gov.br/sites/default/files/publicacoes/indicadoresEconomicos/ INDUruguai.pdf $>$. Acesso em: 6 mar. 2016. 
Tabela 12 - Evolução do Intercâmbio Comercial Brasil.

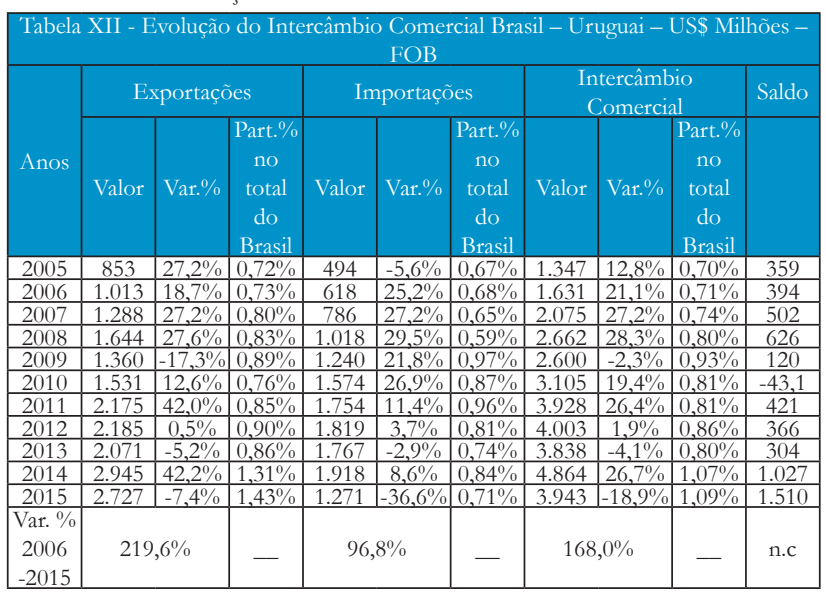

Fonte: MRE, 2016. ${ }^{36}$

Quanto às oportunidades de incrementar as exportações uruguaias para o mercado brasileiro, o Instituto de Promocion de Inversiones y Exportaciones apontou os setores de elaboração de produtos alimentícios, bebidas e tabaco como os mais promissores. No mesmo patamar, encontram-se produtos como carne desossada, arroz, trigo e leite. ${ }^{37}$

Em suma, pode-se afirmar que o intercâmbio comercial entre Brasil e Uruguai vem se desenvolvendo gradativamente nos últimos anos, apresentando grandes benefícios para a economia dos dois países. O Uruguai apresenta-se como um importante parceiro brasileiro no âmbito do Mercosul e o Brasil é o principal destino das exportações uruguaias. Os principais produtos brasileiros exportados para o Uruguai são: combustíveis, automóveis e plásticos. Já os principais produtos uruguaios importados pelo Brasil são: leite, plásticos e automóveis.

A extinção de barreiras tarifárias e não-tarifárias consistem um dos maiores desafios para se alcançar um livre fluxo de bens entre os dois países. As principais barreiras não tarifárias são as medidas sanitárias e fitossanitárias bem como as normas técnicas adotadas pelos dois países. A fim de se solucionar esses entraves, Thorstensen e Kotzias sugerem um exercício de

36 BRASIL. Ministério das Relações Exteriores. Uruguai: comércio exterior. 2016. Disponível em: <http://www.investexportbrasil. gov.br/sites/default/files/publicacoes/indicadoresEconomicos/ INDUruguai.pdf $>$. Acesso em: 6 mar. 2016.

37 URUGUAI. Instituto de Promocíon de Inversiones y Exportaciones (Uruguay 21). Rio Grande do Sul (Brasil): perfil regional. 2014. Disponível em: <http://www.uruguayxxi.gub.uy/ exportaciones/wp-content/uploads/sites/2/2014/09/InformeUru-XXI-Brasil-Agosto-2014.pdf>. Acesso em: 31 mar. 2015. coerência regulatória entre Brasil e Uruguai a fim de conceder maior convergência às normas que regulam o comércio entre os dois países. ${ }^{38}$ Uma vez examinada a realidade do comércio bilateral de bens entre Brasil e Uruguai, parte-se para a análise das principais inciativas de integração produtiva fomentadas pelo GAN.

\section{INICIATIVAS DE INTEGRAÇÃO PRODUTIVA ENTRE Brasil Urugual}

Desde instituição do GAN, Brasil e Uruguai têm avançado consideravelmente na execução dos projetos de integração produtiva voltados a aumentar a competitividade e a complementariedade de suas empresas. Tendo em vista a importância dessas iniciativas para melhorar a integração econômica no Mercosul, parte-se para a análise de três casos específicos: (i) o programa piloto de segurança aduaneira da cadeia de suprimento de bens; (ii) o Acordo Naval e Offshore; e (iii) a integração energética por meio da construção do Parque Eólico de Artilleros (URG).

Em 17 de julho de 2014, os diretores da Receita Federal do Brasil e da Dirección Nacional de Aduanas (Uruguai) firmaram o projeto Programa Piloto de Segurança Aduaneira da Cadeia de Suprimento de Bens, mediante o qual as aduanas se comprometem a conceder um tratamento diferenciado aos operadores habilitados, oferecendo maior agilidade e simplificação de procedimentos aduaneiros. ${ }^{39}$

Esse programa encontra-se previsto no $73^{\circ}$ Protocolo Adicional ao ACE $\mathrm{n}^{\circ} 2$, que devido a procedimentos de internalização de cada Estado-Parte, ainda não se encontra plenamente em vigor. No entanto, ante os objetivos do presente estudo, cumpre analisar os seus principais objetivos, características e peculiaridades.

O projeto tem por principal finalidade estabelecer um programa piloto, com alcance limitado a determinadas cadeias de operações do comércio bilateral Brasil-

38 THORSTENSEN, Vera; KOTZIAS, Fernanda. Integração regulatória: uma proposta de coerência, convergência e cooperação para modernização do Mercosul. Boletim de Economia e Política Internacional, n. 20, p. 21-29, maio/ago. 2015.

39 URUGUAI. Dirección Nacional de Aduanas. Brasil y Uruguay firman acuerdo de seguridad aduanera en la cadena de suministro. Disponível em: $\quad<$ http://www.aduanas.gub.uy/innovaportal/v/12707/9/ innova.front $>$. Acesso em: 27 fev. 2015. 
-Uruguai, com respaldo em critérios técnicos e objetivos e cujas características sejam consideradas apropriadas para uma base de teste. Ao final, com base na experiência adquirida no desenvolvimento do mecanismo de validação das definições estabelecidas para o programa piloto, avançar-se-á no estabelecimento de mecanismos de reconhecimento mútuo. ${ }^{40}$

Dentre suas finalidades específicas, destacam-se as de: (i) definir e identificar, a partir de critérios técnicos e objetivos, o universo de operadores de interesse para o programa; (ii) definir os requisitos para a adesão de empresas e o tratamento diferenciado no controle aduaneiro sobre suas operações de comércio exterior; (iii) estabelecer um modelo comum de validação dos requisitos e dos benefícios aduaneiros com a finalidade de se realizar reconhecimento mútuo; e (iv) formular um acordo de reconhecimento mútuo. ${ }^{41}$

A partir da sua execução, espera-se que o programa-piloto atinja diversos resultados positivos, como, o fortalecimento do controle aduaneiro, elevando-se o nível de segurança aduaneira, fiscal e comercial das operações de importação e exportação efetuadas entre os países; celeridade, simplificação e racionalização para os trâmites aduaneiros de exportação e importação entre os países, que deverão estabelecer acordos bilaterais de reconhecimento mútuo; otimização dos recursos humanos aduaneiros para outras operações consideradas de maior risco; criação de confiança entre as aduanas e promoção do comércio entre os dois países. ${ }^{42}$

Ademais, cabe à administração aduaneira de cada país selecionar as empresas participantes do programa piloto que deverá se pautar pelo princípio da confiança mútua. Assim, participam do projeto três empresas exportadoras uruguaias e três brasileiras, além de transportadoras e despachantes, totalizando 18 empresas

40 URUGUAI. Dirección Nacional de Aduanas. Proyecto de programa piloto de seguridad aduanera en la cadena de suministro Brasil - Uruguay. Disponível em: <http://www.aduanas.gub.uy/innovaportal/ file/12605/1/proyecto_de_ppsacs_brasil-uruguay_-_espanol.pdf $>$. Acesso em: 27 fev. 2015.

41 URUGUAI. Dirección Nacional de Aduanas. Proyecto de programa piloto de seguridad aduanera en la cadena de suministro Brasil - Uruguay. Disponível em: <http://www.aduanas.gub.uy/innovaportal/ file/12605/1/proyecto_de_ppsacs_brasil-uruguay_-_espanol.pdf $>$. Acesso em: 27 fev. 2015.

42 URUGUAI. Dirección Nacional de Aduanas. Proyecto de programa piloto de seguridad aduanera en la cadena de suministro Brasil - Uruguay. Disponível em: <http://www.aduanas.gub.uy/innovaportal/ file/12605/1/proyecto_de_ppsacs_brasil-uruguay_-_espanol.pdf $>$. Acesso em: 27 fev. 2015. envolvidas no programa piloto. As empresas selecionadas gozam de benefícios específicos, como a redução do tempo de espera na fronteira e a simplificação dos trâmites aduaneiros, tanto na saída como na entrada da aduana, o que resultará na redução substancial dos custos associados. ${ }^{43}$

Uma vez assegurado o cumprimento das obrigações por parte dos operadores envolvidos no programa, as aduanas poderão dedicar maior atenção aos operadores de elevado risco aduaneiro, o que trará maior eficiência às administrações aduaneiras tanto do Brasil quanto do Uruguai.

Todavia, cumpre salientar que o programa piloto não alcança cadeias operacionais de comércio intrarregional realizadas por via marítima ou aérea. O projeto se limita a determinadas cadeias logísticas baseadas no comércio bilateral por via terrestre. ${ }^{44}$ Em razão do elevado número de operações aduaneiras, o programa piloto será executado em dois postos de fronteira específicos: Jaguarão (BRA) - Rio Branco (URU) e Chuí (BRA) - Chuy (URU).$^{45}$ Ressalta-se que o projeto piloto em questão se inspira no Programa IntraMercosul de Segurança Aduaneira da Cadeia de Suprimentos de Bens. ${ }^{46}$

Por fim, destaca-se que o Uruguai possui acordo similar com a Argentina. Em 4 de novembro de 2014, a Administración Federal de Ingressos Públicos (ARG) e a Dirección Nacional de Aduanas (URG) firmaram o Acordo para Implementação Bilateral do Programa Piloto IntraMercosul de Segurança Aduaneira da Cadeia de Suprimento de Bens. ${ }^{47} \mathrm{O}$ projeto também se encontra em

43 URUGUAI. Dirección Nacional de Aduanas. Proyecto de programa piloto de seguridad aduanera en la cadena de suministro Brasil - Uruguay. Disponível em: <http://www.aduanas.gub.uy/innovaportal/ file/12605/1/proyecto_de_ppsacs_brasil-uruguay_-_espanol.pdf>. Acesso em: 27 fev. 2015.

44 BRASIL Ministério das Relações Exteriores. Brasil e Uruguai investem em novo paradigma de integração. 2015. Disponível em: < http:// diplomaciapublica.itamaraty.gov.br/40-brasil-uruguai $>$. Acesso em: 28 abr. 2015.

45 URUGUAI. Dirección Nacional de Aduanas. Proyecto de programa piloto de seguridad aduanera en la cadena de suministro Brasil - Uruguay. Disponível em: <http://www.aduanas.gub.uy/innovaportal/ file/12605/1/proyecto_de_ppsacs_brasil-uruguay_-_espanol.pdf $>$. Acesso em: 27 fev. 2015.

46 URUGUAI. Dirección Nacional de Aduanas. Proyecto de programa piloto de seguridad aduanera en la cadena de suministro Brasil - Uruguay. Disponível em: <http://www.aduanas.gub.uy/innovaportal/ file/12605/1/proyecto_de_ppsacs_brasil-uruguay_-_espanol.pdf $>$. Acesso em: 27 fev. 2015.

47 URUGUAI. Dirección Nacional de Aduanas. Proyecto de programa piloto de seguridad aduanera en la cadena de suministro Brasil - Uruguay. 
fase piloto, ainda não sendo possível mensurar todos os seus resultados.

O Acordo Naval e Offshore, por sua vez, foi assinado durante a II Reunião Plenária do Subgrupo de Integração Produtiva do Grupo de Alto Nível Bilateral (GAN) realizada em 15 de maio de 2014. Ele constitui o $74^{\circ}$ Protocolo Adicional ao ACE n ${ }^{\circ} 02$ e visa à integração das cadeias produtivas regionais no setor naval e offshore e ao acesso recíproco de bens e serviços dos dois países no setor.

Nesse sentido, o Acordo promove o acesso recíproco de bens e serviços de empresas brasileiras e uruguaias, bem como estabelece o reconhecimento mútuo de conteúdo local, desde que a certificação seja realizada por empresa brasileira responsável pela certificação que atue tanto no Brasil quanto no Uruguai, e tenha a chancela de certificação realizada por técnico credenciado junto à autoridade competente do Estado importador. $^{48} \mathrm{O}$ acordo também dispõe sobre a formação de um Comitê Naval e Offshore Bilateral, coordenado no Brasil pelo Ministério do Desenvolvimento Indústria e Comércio Exterior. (MDIC) e no Uruguai pelo ministério correspondente.

O Acordo Naval e Offshore é considerado um marco, visto que eleva o setor naval a um grau prioritário, que, ao lado do automotivo, já é considerado entre os segmentos com maior integração e complementariedade entre os países do Mercosul, conforme pronunciamento do ministro do MDIC à época, Mauro Borges. ${ }^{49} \mathrm{O}$ documento é resultado do esforço conjunto realizado pelo Ministério do Desenvolvimento, Indústria e Comércio, o Ministério das Relações Exteriores, o Ministério dos Transportes e a Agência Nacional do Petróleo para a integração produtiva bilateral naval.

O projeto de integração energética já tinha sido inicialmente previsto Comunicado Conjunto Presidencial que estabeleceu o GAN em 31 de julho de 2012. Na ocasião, Brasil e Uruguai já demonstravam interesse em consolidar uma proposta de integração dos sistemas

Disponível em: <http://www.aduanas.gub.uy/innovaportal/ file/12605/1/proyecto_de_ppsacs_brasil-uruguay_-_espanol.pdf > . Acesso em: 27 fev. 2015.

48 No Brasil, o responsável é a Agência Nacional do Petróleo (ANP).

49 BRASIL. Ministério do Desenvolvimento Indústria e Comércio Exterior. Brasil e Uruguai assinam acordo no setor naval. 2014. Disponível em:< http://www.mdic.gov.br/sitio/interna/noticia. php?area $=2 \&$ noticia $=13174>$. Acesso em: 2 maio 2015 . eletroenergéticos que incluísse aspectos de operação comercialização, regulação e planejamento da expansão do sistema. ${ }^{50}$

Assim, os Presidentes reconheceram a importância da construção de uma linha de transmissão de $500 \mathrm{KV}$ entre San Carlos (Uruguai) e Candiota (Brasil), bem como a relevância da associação entre a Eletrobrás e $a$ Administración Nacional de Usinas y Trasmisiones Eléctricas (UTE) para a construção de parque um eólico no Uruguai.

Essa cooperação resultou na construção do Parque Eólico de Artilleros no Uruguai, inaugurado em 1o de março de 2015 pela Presidente Dilma Rousseff e pelo Presidente José Mujica. Ressalta-se que Artilleros é o primeiro projeto de geração de energia eólica da Eletrobras fora do Brasil, sendo financiado pela Corporación Andina de Fomento (CAF). Aliás, cumpre salientar que a sua inauguração constitui importante realização do GAN, uma vez que esse projeto foi uma das primeiras ações delineadas pelo grupo.

Em artigo redigido para o jornal El Pais em $1^{\circ}$ de março de 2015, a Presidenta do Brasil expressou satisfação com os avanços alcançados na integração bilateral e reafirmou sua determinação em seguir adiante com esse caminho. Para tanto, a Presidenta ratificou a importância do GAN que, na prática, compromete-se com a busca por uma maior complementação industrial, crescente dinamismo na integração da infraestrutura, maior fluidez nas fronteiras, maior e melhor comércio, bem como a consolidação da interconexão energética entre os dois países. ${ }^{51}$

Em entrevista concedida por ocasião da Inauguração do Parque Eólico de Artilleros, o Ex-Presidente do Uruguai, José Mujica, exaltou a sintonia entre Brasil e Uruguai em prol do desenvolvimento regional, afirmando que a relação com o governo brasileiro tem sido muito fluida em todos esses anos, tanto do ponto de vista comercial, quanto do ponto de vista político. Mujica reiterou, também, a posição estratégica do Brasil como incontestável liderança política regional, alegando que, apesar de o Brasil ser um país gigantesco para a

50 URUGUAI. Dirección Nacional de Aduanas. Proyecto de programa piloto de seguridad aduanera en la cadena de suministro Brasil - Uruguay. Disponível em: <http://www.aduanas.gub.uy/innovaportal/ file/12605/1/proyecto_de_ppsacs_brasil-uruguay_-_espanol.pdf $>$. Acesso em: 27 fev. 2015.

51 ROUSSEFF, Dilma. Uruguay e Brasil: un nuevo paradigma. El pais, Montevidéu, 1 mayo 2015. 
escala uruguaia, eles se sentem muito integrados. ${ }^{52}$

Em 21 de maio de 2015, o novo Presidente da República Oriental do Uruguai, Tabaré Vázquez, realizou visita de Estado ao Brasil, atendendo ao convite da Presidenta Dilma Rousseff. Desde que -tomou posse em $1^{\circ}$ de março de 2015, essa foi a primeira visita bilateral do Presidente Uruguai ao exterior. Nesta ocasião, os Presidentes mantiveram produtiva reunião de trabalho, dando seguimento aos temas da ampla agenda bilateral. ${ }^{53}$

Sobre os novos projetos em comum, os Presidentes destacaram a conclusão das obras da nova linha de transmissão entre Candiota (Brasil) e San Carlos (Uruguai), no plano da interconexão elétrica bilateral. Segundo estimativas do governo brasileiro, a linha de transmissão de 411 quilômetros entre Candiota e San Carlos viabilizará a integração física do sistema elétrico brasileiro e uruguaio, permitindo o aproveitamento das complementariedades energéticas entre os dois países. Esse projeto é financiado por recursos do Uruguai e do Fundo de Convergência Estrutural (FOCEM) e se soma ao Parque Eólico de Artilleros. ${ }^{54}$

Diante do exposto, pode-se afirmar que a iniciativa da instituição do Grupo de Alto Nível Brasil - Uruguai constitui um bom exemplo a ser seguido pelos outros Estados-Parte do Mercosul, haja vista institui uma agenda positiva que consegui avançar em questões de grade relevância para a integração produtiva dos dois países.

\section{Considerações finais}

Apesar de a comercialização de bens intra e extraMercosul estar apresentando crescimento contínuo, ainda há espaço para que a agenda de liberalização de

52 BRASIL. Presidência da República. José Mujica exalta sintonia entre Brasil e Uruguai em prol do desenvolvimento regional: depoimento. 2015. Entrevista concedida ao Blog do Planalto em 2 de março de 2015. Disponível em: <http://blog.planalto.gov.br/jose-mujica-exaltasintonia-entre-brasil-e-uruguai-em-prol-do-desenvolvimentoregional/>. Acesso em: 29 abr. 2015.

53 BRASIL. Ministério das Relações Exteriores. Declaração à imprensa da Presidenta da República, Dilma Rousseff, após encontro com o Presidente do Uruguai, Tabaré Vázquez: Brasilia, 2015. Disponível em: <http://goo.gl/fwrx3I>. Acesso em: 21 maio 2015.

54 BRASIL. Ministério das Relações Exteriores. Declaração à imprensa da Presidenta da República, Dilma Rousseff, após encontro com o Presidente do Uruguai, Tabaré Vázquez. Brasília, 2015. Disponível em: <http://goo.gl/fwrx3I>. Acesso em: 21 maio 2015. bens seja realmente efetivada no âmbito do bloco. Os desafios se referem tanto à diminuição das listas de exceções quanto à redução das barreiras não tarifárias. A China apresenta-se como o principal parceiro comercial do Mercosul, tanta nas importações quanto nas exportações do bloco. Assim, seria interessante elaborar uma política conjunta do Mercosul com relação à China, diante da já significante presença desse país na América do Sul.

O intercâmbio comercial entre Brasil e Uruguai vem se desenvolvendo gradativamente nos últimos anos, apresentando grandes benefícios para a economia dos dois países. O Uruguai apresenta-se como um importante parceiro brasileiro no âmbito do Mercosul e o Brasil é o principal destino das exportações uruguaias. Os principais produtos brasileiros exportados para o Uruguai são: combustíveis, automóveis e máquinas mecânicas. Já os principais produtos uruguaios importados pelo Brasil são: cereais, plásticos e leite

Assinala-se a importância do Programa Piloto de Segurança Aduaneira da Cadeia de Suprimento de Bens para o aprofundamento das relações comerciais entre Brasil e Uruguai. Esse projeto apresenta-se como um importante passo para a formação de cadeias globais de valor, haja vista que atende, inicialmente, a empresas com baixo risco aduaneiro e relevantes operações comerciais entre os dois países. Além de que, a partir da sua execução, poder-se-á formular um acordo de reconhecimento mútuo.

O Acordo Naval e Offshore eleva o setor marítimo a um grau prioritário no processo de integração produtiva desenvolvido por Brasil e Uruguai. Esse marco legal promove o acesso recíproco de bens e serviços de empresas brasileiras e uruguaias, bem como estabelece o reconhecimento mútuo de conteúdo local. Assim, promove-se a integração e complementariedade desse segmento, aumentando-se a competitividade das empresas envolvidas no mercado internacional.

A construção do Parque Eólico de Artilleros no Uruguai, por sua vez, apresenta-se como uma grande vitória alcançada pelo GAN, haja vista que esse projeto foi uma das primeiras ações delineadas pelo grupo. Ademais, fica demonstrado a seriedade das iniciativas levadas a cabo pelos dois países, uma vez que a integração da produção energética entre dois países se caracteriza como tema estratégico nas relações internacionais. A entrada em funcionamento do parque eólico irá re- 
forçar a segurança energética dos dois países, bem aumentar a competitividade das suas empresas, que terão acesso a uma tarifa de energia mais baixa.

Em síntese, pode-se afirmar que as iniciativas de integração produtiva do GAN deveriam ser replicadas no âmbito do Mercosul, especialmente, o programa piloto de segurança aduaneira da cadeia de suprimento de bens; o Acordo Naval e Offshore; e a integração energética por meio da implantação de fontes de energia renovável, como o Parque Eólico de Artilleros

\section{REFERÊNCIAS BIBLIOGRÁFICAS}

AMARAL JÚNIOR, Alberto do. Curso de direito internacional público. 4 ed. São Paulo: Atlas, 2013.

BALDWIN, Richard. 21 Century regionalism: filling the gap between 21 century trade and 20 century trade rules. Geneva: WTO, 2011.

BRASIL. Ministério das Relações Exteriores. Mercosul. Disponível em: <http://www.itamaraty.gov.br/index. php?option $=$ com_content $\& v i e w=$ article $\&$ id $=686:$ mer cosul\&catid $=143 \&$ Itemid $=434 \&$ lang $=p t-B R>$. Acesso em: 13 jun. 2015.

BRASIL. Ministério das Relações Exteriores. Mercosul: comércio exterior. 2015. Disponível em: <http://www. investexportbrasil.gov.br/sites/default/files/publicacoes/indicadoresEconomicos/ComExtMERCOSUL. pdf $>$. Acesso em: 5 mar. 2016.

BRASIL. Ministério das Relações Exteriores. Mercosul: comércio exterior: intercâmbio comercial com o Brasil. 2015. Disponível em: <http://www.brasilexport.gov. $\mathrm{br} /$ sites/default/files/publicacoes/indicadoresEconomicos/ComExtMERCOSUL.pdf $>$. Acesso em: 27 ago. 2015.

BRASIL. Ministério das Relações Exteriores. Comunicado conjunto presidencial: novo paradigma para relação Brasil Uruguai. Nota 192, 31 julho de 2012. Disponível em: < http:/ /goo.gl/M6DA7r>. Acesso em: 27 abr. 2015.

BRASIL Ministério das Relações Exteriores. Brasil e Uruguai investem em novo paradigma de integração. 2015. Disponível em: <http://diplomaciapublica.itamaraty.gov. br/40-brasil-uruguai>. Acesso em: 28 abr. 2015.

BRASIL. Ministério Das Relações Exteriores. Uruguai: comércio exterior. Dezembro, 2014, p. 9. Disponível em: <http://www.brasilexport.gov.br/sites/default/ files/publicacoes/indicadoresEconomicos/INDUruguai.pdf $>$. Acesso em: 30 mar. 2015.

BRASIL. Ministério das Relações Exteriores. Declaração à imprensa da Presidenta da República, Dilma Rousseff, após encontro com o Presidente do Uruguai, Tabaré Vázquez. Brasilia, 2015. Disponível em: <http://goo.gl/fwrx3I>. Acesso em: 21 maio 2015.

BRASIL. Ministério das Relações Exteriores. Uruguai: comércio exterior. 2016. Disponível em: <http://www. investexportbrasil.gov.br/sites/default/ files/publicacoes/indicadoresEconomicos/INDUruguai.pdf $>$. Acesso em: 6 mar. 2016.

BRASIL. Ministério das Relações Exteriores. Uruguai: comércio exterior. Junho 2015. Disponível em: <http://www.brasilexport.gov.br/sites/default/files/ publicacoes/indicadoresEconomicos/INDUruguai. pdf> Acesso em: 22 jul. 2015.

BRASIL. Ministério das Relações Exteriores. Acordo de complementação econômica $n^{\circ} 2$, celebrado entre a República Federativa do Brasil e a República Oriental do Uruguai. Disponível em: <http://dai-mre.serpro.gov.br/atosinternacionais/multilaterais/acordo-de-complementacao-economica-nb0-2-celebrado-entre-a-republica-federativa-do-brasil-e-a-republica-oriental-do-uruguai/ $>$. Acesso em: 2 mar. 2015.

BRASIL. Ministério do Desenvolvimento, Indústria e Comércio Exterior. Lista de exceções à tarifa externa comum - LETEC. Disponível em: <http://www. desenvolvimento.gov.br/sitio/interna/interna. php?area $=5 \&$ menu $=3378>$. Acesso em: 2 maio 2015.

BRASIL. Ministério do Desenvolvimento, Indústria e Comércio Exterior. Tipos de acordos no âmbito da ALADI. Disponível em: <http://www.desenvolvimento.gov.br/ sitio $/$ interna $/$ interna.php?area $=5 \&$ menu $=412>$. Acesso em: 11 mar. 2016.

BRASIL. Ministério do Desenvolvimento Indústria e Comércio Exterior. Brasil e Uruguai assinam acordo no setor naval. 2014. Disponível em: < http://www.mdic.gov. $\mathrm{br} / \mathrm{sitio} /$ interna $/$ noticia. php?area $=2 \&$ noticia $=13174>$. Acesso em: 2 maio 2015.

BRASIL. Presidência da República. José Mujica exalta sintonia entre Brasil e Uruguai em prol do desenvolvimento regional: depoimento. 2015. Entrevista concedida ao Blog do Planalto em 2 de março de 2015. Disponível em: 
$<$ http:/ /blog.planalto.gov.br/jose-mujica-exalta-sintonia-entre-brasil-e-uruguai-em-prol-do-desenvolvimento-regional/>. Acesso em: 29 abr. 2015.

CELLI JUNIOR, Umberto; ELEOTERIO, Belisa. O Brasil, o Mercosul e os acordos preferenciais de comércio: alternativas e perspectivas. In: IGLESIAS, Enrique et al. (Org.). Os desafios da América Latina no século 21. Curitiba: Juruá, 2014.

OELSNER, Andrea. The institutional identity of regional organizations, or mercosur's identity crisis. International Studies Quartely, v. 57, p. 115-127, 2013.

PRAZERES, Tatiana. A OMC e os blocos regionais. São Paulo: Aduaneiras, 2008.

ROUSSEFF, Dilma. Uruguay e Brasil: un nuevo paradigma. El pais, Montevidéu, 1 mayo 2015.

THORSTENSEN, Vera; KOTZIAS, Fernanda. Integração regulatória: uma proposta de coerência, convergência e cooperação para modernização do Mercosul. Boletim de Economia e Política Internacional, n. 20, p. 21-29, maio/ago. 2015.

URUGUAI. Instituto de Promocíon de Inversiones y Exportaciones (Uruguay 21). Rio Grande do Sul (Brasil): perfil regional. 2014. Disponível em: <http://www. uruguayxxi.gub.uy/exportaciones/wp-content/uplo-
ads/sites/2/2014/09/Informe-Uru-XXI-Brasil-Agosto-2014.pdf >. Acesso em: 31 mar. 2015.

URUGUAI. Dirección Nacional de Aduanas. Anuario Dirección Nacional de Aduanas Uruguay 2014: construyendo futuro. Disponível em: <http://www.aduanas.gub. uy/innovaportal/file/13215/1/anuario_dna_2014. pdf>. Acesso em: 27 fev. 2015.

URUGUAI. Dirección Nacional de Aduanas. Brasil y Uruguay firman acuerdo de seguridad aduanera en la cadena de suministro. Disponível em: <http://www.aduanas.gub. uy/innovaportal/v/12707/9/innova.front>. Acesso em: 27 fev. 2015.

URUGUAI. Dirección Nacional de Aduanas. Proyecto de programa piloto de seguridad aduanera en la cadena de suministro Brasil - Uruguay. Disponível em: <http://www. aduanas.gub.uy/innovaportal/file/12605/1/proyecto_de_ppsacs_brasil-uruguay_-_espanol.pdf $>$. Acesso em: 27 fev. 2015.

\section{Notas das Tabelas}

1 Dados obtidos por espelho, ou seja, pela informação dos parceiros, portanto em constante atualização.

2 Exceto combustíveis.

3 Dados obtidos por espelho, ou seja, pela informação dos parceiros, portanto em constante atualização. 
Para publicar na Revista de Direito Internacional, acesse o endereço eletrônico www.rdi.uniceub.br ou www.brazilianjournal.org.

Observe as normas de publicação, para facilitar e agilizar o trabalho de edição. 